\title{
Stimulus intensity dynamism with stimuli equal decibel distances above and below background
}

\author{
JOHN C. BIRKIMER and DOROTHY L. DRANE, ${ }^{1}$ University of \\ Louisville, Louisville, Ky. 40208
}

The discriminated lever-press shock-avoidance performance of four rats was observed to two white noise warning signals, one 5 $d B$ above and the other $5 \mathrm{~dB}$ below the white noise background level. Although the warning signals might be expected to elicit equal generalized inhibitory tendencies and might be viewed as involving equal stimulus change from background, three of the four Ss each showed significantly greater performance to the higher intensity warning signal and the fourth significantly poorer performance to that stimulus.

Stimulus intensity dynamism (SID), as used descriptively by Gray (1965a, pp. 180-181), is a positive relationship between stimulus intensity and response magnitude. In his review, Gray discussed the Perkins (1953)-Logan (1954) interpretation of SID as a phenomenon due to generalization of inhibition from an unreinforced zero or background intensity stimulus. Several recent studies have examined the ability of generalization of inhibition to produce SID-like gradients.

Gray (1965b), in an unpublished study, found a negative relationship between discriminative stimulus $\left(S_{D}\right)$ intensity and response rate in rats when responses to several $S_{D}$ intensities were reinforced but those to the most intense $S_{D}$ were not reinforced, demonstrating that generalization of inhibition from the unreinforced highest intensity $\mathrm{S}_{\mathrm{D}}$ did occur and produced a reversed SID gradient.

Two recent studies have further demonstrated the ability of nonreinforcement of a highest intensity stimulus to reverse typical SID gradients. Birkimer \& James (1967) presented four intensities of white noise to rats in a discriminated instrumental lever press avoidance task. After performance to the warning signals had stabilized, nonreinforcement (no shock programmed) of the highest intensity warning signal reduced responding to the second highest intensity. James \& Mostoway (1968) tested two groups of rats in a food-reinforced lever press situation with four intensities of discriminative stimuli being presented. Group L, for whom all $S_{D} s$ but the lowest were reinforced, showed a typical SID gradient. Group $\mathrm{H}$, with all $\mathrm{S}_{\mathrm{D}} \mathrm{S}$ reinforced except the highest, showed a reversed gradient. Reversing the treatments of the two groups, so that Group $L$ received nonreinforcement to the highest $S_{D}$ and Group $H$ to the lowest, reversed the direction of each group's gradient, thus demonstrating the ability of inhibitionproducing operations to yield SID gradients. However, the response rates emitted to the nonreinforced low intensity $S_{D}$ were reliably lower than those emitted to the nonreinforced high intensity $S_{D}$, suggesting a possible dynamogenic effect of stimulus intensity.

The Gray (1965b), Birkimer \& James (1967) and James \& Mostoway (1968) studies all involved alternating periods of $S_{D}$ or warning signal and background. Consequently, the further a stimulus was from background, the greater the change in stimulus intensity which accompanied its onset. Grice, Masters, \& Kohfeld (1966) conducted a study designed to examine the ability of amount of stimulus change to produce SID effects, but to eliminate the usually confounded generalization of inhibition effect by having no consistent background. Using humans in a classically conditioned eye-blink situation, they presented one of three intensities of tone, then shifted to a second, using the change in intensity as the CS. The second intensity remained until the next change, the next CS, and so forth. Trials were arranged so that each intensity was present for equal total time periods, and a greater percentage CR was obtained to CSs involving greater stimulus change, with little or no effect of direction of change to more or less intense stimulation. Perhaps their results can be predicted from consideration of the inhibition developed to each intensity during the inter-CS intervals and its generalization. Their finding of little or no effect of direction of change is surprising in light of James and Mostoway's discovery of greater responding to higher intensity negative $S_{D}$ s.

The present study attempted to hold constant both generalization of inhibition and also amount of stimulus change from background, seeking any residual dynamogenic effect of stimulus intensity itself. If one assumes that generalization of inhibition gradients are symmetric, then by setting an above ambient level intensity as background and presenting two stimuli equally distant from that background, but one more intense and one less intense, the amount of generalized inhibition and of stimulus change should be identical for the two stimuli. This procedure was used in a discriminated lever press avoidance task. Generalization of inhibition gradients were assumed symmetric over a decibel scale, in line with the Hullian suggestion that generalized conditioned inhibition varies with the distance between stimuli on a JND or log unit dimension (Hilgard, 1956, p. 140).

\section{METHOD}

Four naive male Sprague-Dawley rats approximately 120 days old were trained on a discriminated lever press avoidance task in a Lehigh Valley operant conditioning chamber (1316). The warning signals (WS) were two intensities of white noise, $89 \mathrm{~dB}$ (high) (re .0002 dynes $/ \mathrm{cm}^{2}$ ) and $79 \mathrm{~dB}$ (low), equally distant from the background white noise intensity of $84 \mathrm{~dB}$ (Bruel \& Kjaer Model No. 4133 sound level meter). Bàckground level was continuously present during the intertrial interval. A $5 \mathrm{sec}$ interstimulus interval (ISI) followed the onset of each WS, high or low, and preceded the first shock on each trial. Shocks of $.7 \mathrm{~mA}$ were presented intermittently at $.3 \mathrm{sec}$ on, $2 \mathrm{sec}$ off, and escape from shock was prevented during the $.3 \mathrm{sec}$ shock periods. Trials were presented on a variable interval $50 \mathrm{sec}$ schedule.

After being trained to escape continuous shock, Ss received a 6 $\mathrm{h}$ avoidance training session every $48 \mathrm{~h}$ with the two WSs presented randomly. A WS, high or low, was presented and, if the $S$ responded within the ISI, no shock occurred and the WS terminated, restoring background intensity. If the $S$ did not respond during the ISI, the WS remained on and intermittent shock was presented until the $S$ responded. Training continued until the avoidance performance of each $S$ had been reasonably assessed.

\section{RESULTS}

A recording malfunction invalidated data from the early training sessions. Consequently, all analyses involve data collected after Session 15. Aperiodic observation of Ss indicated that lever holding was not a problem. thus differential startle did not contaminate the results. Cumulative records indicated that intertrial responding dropped to near zero over the first several sessions, so correction of avoidance responses was not required.

Table 1 shows the percentage avoidance (number of avoidances divided by number of trials) for each $S$ to each WS over days. Ss 1 , 2 , and 4 showed a greater percentage avoidance to the high WS on 9 of 9 days, 9 of 9 days, and 11 of 14 days, respectively. S 3, on the other hand, showed greater percentage avoidance to the low WS on 12 of 14 days.

For each $S$, the probability of the observed number of days with performance greater to high than to low was calculated, under the null hypothesis that performance to high was equal to or less than that to low. The binomial expansion, $p=\sum_{r=x}^{n} C_{r}^{n}$ $p^{r} q^{(n-r)}$, was calculated for each $S$, with $n$ the number of days $S$ was run, $x$ the number of days $S$ showed greater performance to high than to low, $p$ equal to one-half (the probability of performance to high being greater than performance to low under the null hypothesis), and q likewise equal to one-half. The obtained probabilities for Ss 1 through 4 , respectively, were .002 , $.002, .994$, and .029 , forcing, for each $S$ except 3 , acceptance of 
Table 1

Percentage Avoidance for Each of Four Ss to Both High (H) and Low (L) WSs

\begin{tabular}{|c|c|c|c|c|c|c|c|c|}
\hline & & & & Sub & Iumb & & & \\
\hline & & & & & & & & \\
\hline & & & & & & & & \\
\hline Day & $\mathrm{H}$ & $\mathrm{L}$ & $\mathrm{H}$ & $\mathbf{L}$ & H & $\mathrm{L}$ & $\mathbf{H}$ & $\mathbf{L}$ \\
\hline 16 & $\ldots$ & - & - & - & 7.1 & 9.1 & 0.0 & 1.1 \\
\hline 17 & 24.8 & 15.0 & 10.7 & 1.0 & 4.1 & 11.8 & 5.3 & 2.9 \\
\hline 18 & 22.1 & 15.1 & 13.8 & 3.3 & 7.9 & 9.3 & 1.8 & 2.9 \\
\hline 19 & 21.7 & 17.9 & 11.9 & 4.9 & $3: 4$ & 3.7 & 2.4 & 1.8 \\
\hline 20 & 25.9 & 17.0 & 25.2 & 10.1 & 7.5 & 8.3 & 1.7 & 1.0 \\
\hline 21 & 32.6 & 26.3 & 20.9 & 4.5 & 9.2 & 6.2 & 5.0 & 5.8 \\
\hline 22 & 28.5 & 22.7 & 14.5 & 5.1 & 11.0 & 8.7 & 7.5 & 2.2 \\
\hline 23 & 29.3 & 28.4 & 17.7 & 5.0 & 3.8 & 6.0 & 4.9 & 3.1 \\
\hline 24 & 33.8 & 21.7 & 13.3 & 4.7 & 6.4 & 9.7 & 3.8 & 3.2 \\
\hline 25 & 32.2 & 22.3 & 21.2 & 7.3 & 3.3 & 10.1 & 6.6 & 5.7 \\
\hline 26 & - & - & - & - & 2.6 & 5.9 & 14.2 & 10.6 \\
\hline 27 & - & - & - & - & 2.7 & 4.5 & 7.3 & 3.4 \\
\hline 28 & - & - & - & - & 2.1 & 2.4 & 7.5 & 5.9 \\
\hline 29 & - & - & - & - & 3.4 & 8.0 & 8.3 & 5.4 \\
\hline
\end{tabular}

the alternative hypothesis, that performance to high was greater than that to low.

The obtained probabilities for each of the four Ss were combined for a group test of the null hypothesis that they constituted a random sample from a population with a mean of one-half. (This is equivalent to hypothesizing that the group as a whole showed similar levels of performance to high and to low.) $x^{2}=\sum_{i=1}^{n}-1 n$ pi with $\mathrm{d} f=2 \mathrm{n}$ (Winer, 1962, pp. 43-44) was calculated, yielding a value of 31.876 with $\mathrm{df}=8$, significant beyond the .001 level. Thus the group of Ss as a whole showed significantly greater percentage avoidance to the high WS.

The probability of S 3 's performance, under the null hypothesis discussed above, was calculated as .994 , though the present analysis would yield a probability of .500 if S's performance were greater to the high WS on half the days. Consequently, a reversed null hypothesis, that performance to high is equal to or greater than that to low, was tested for this S. The binomial was recalculated, using as $\mathrm{x}$ the number of days on which performance was poorer to the high WS, with $\mathrm{n}, \mathrm{p}$, and $\mathrm{q}$ as before. Under the reversed null hypothesis a probability of .006 was obtained, suggesting acceptance of the alternative that this $S$ showed reliably greater performance to the low intensity WS, a reversed SID effect.

\section{DISCUSSION}

Three of the four Ss tested showed significantly greater performance to the high intensity WS, the traditional SID effect, and as a group the four Ss yielded the same result. The fourth demonstrated a significant reversed SID effect. These results occurred in spite of the fact that the high and low intensity WSs were equally distant from the intermediate background intensity on a decibel scale. If the assumptions that inhibitory gradients are symmetric over $\mathrm{dB}$ scales and that amount of stimulus change should be measured over this dimension are correct, then the present results suggest a dynamogenic effect of stimulus intensity beyond that attributrible to the inhibition and stimulus change variables.
If a JND or $\mathrm{dB}$ scale does not yield symmetric generalization of inhibition, or is not the appropriate scale for measuring amount of stimulus change, then one of these variables may account for the results. Further, in line with the Grice \& Hunter (1964) suggestion that SID be interpreted in terms of adaptation level theory, perhaps extra-experimental stimulation contributes to the generalized inhibition operative in SID demonstrations. At the present time, however, granting the appropriateness of the $\mathrm{dB}$ scale in this study, generalization of inhibition, amount of stimulus change, and stimulus intensity per se all seem capable of producing SID effects.

Finally, the reversed SID effect shown by $S 3$ is not strictly anomalous. Suppression or freezing is a common response of rats to a warning signal (Meyer, Cho, \& Wesemann, 1960), and freezing precludes avoidance responding. Kamin \& Schaub (1963) demonstrated an SID effect with -conditioned suppression, more suppression to greater intensities of stimuli. If the freezing often found in the discriminated avoidance situation is similar to the conditioned suppression effect, then an SID effect on freezing and a resulting reversed SID effect on avoiding follows. If this explanation is correct, however, the data suggest that the level of avoidance performance necessary to overcome the suppression effect differs across animals; $S 2$ 's performance to the low WS and $S$ 4's overall performance are comparable to $S 3$ 's level of performance, yet these first two Ss showed regular SID effects.

\section{REFERENCES}

BIRKIMER, J. C., \& JAMES, J. P. Stimulus intensity dynamism and generalization of inhibition in a discriminated lever press avoidance situation. Psychonomic Science, 1967, 8, 377-378.

GRAY, J. A. Stimulus intensity dynamism. Psychological Bulletin, 1965a, 63, 180-196.

GRAY, J. A. A test of the generalization of inhibition explanation of stimulus intensity dynamism. 1965b. Unpublished paper discussed in Gray, 1965a, Footnote 4, p. 185.

GRICE, G. G., \& HUNTER, J. J. Stimulus intensity effects depend upon the type of experimental design. Psychological Review, 1964, 71, 247-256.

GRICE, G. G., MASTERS, L., \& KOHFELD, D. I. Classical conditioning without discrimination training: A test of the generalization theory of CS intensity effects. Journal of Experimental Psychology, 1966, 72, 510-513.

HILGARD, E. R. Theories of learning. New York: Appleton-Century-Crofts, 1956.

JAMES, J. P., \& MOSTOWAY, W. W. Stimulus intensity dynamism: Effect of non-reinforcement of the highest intensity stimulus. Paper presented at the meeting of the Canadian Psychological Association, Calgary, Alberta, June, 1968.

KAMIN, L. J., \& SCHAUB, R. E. Effects of conditioned stimulus intensity on the conditioned emotional response. Journal of Comparative and Physiological Psychology, 1963, 56, 502-507.

LOGAN, F. A. A note on stimulus intensity dynamism (V). Psychological Review, 1954, 61, 77-80.

MEYER, D. R., CHO, C., \& WESEMANN, A. F. On problems of conditioning discriminated lever press avoidance responses. Psychological Review, 1960, 67, 224-228.

PERKINS, C. C. The relation between conditioned stimulus intensity and response strength. Journal of Experimental Psychology, 1953, 46, 225-231.

WINER, B. J. Statistical principals in experimental design. New York: McGraw-Hill, 1962.

\section{NOTE}

1. Now at the State University of New York, Buffalo. 